\title{
Airflow and Heat Transfer in the Slot-Vented Room with Radiant Floor Heating Unit
}

\author{
Xiang-Long Liu, ${ }^{1,2}$ Guang-Cai Gong, ${ }^{1}$ \\ Heng-Sheng Cheng, ${ }^{3}$ and Li-Xing Ding ${ }^{4}$ \\ ${ }^{1}$ School of Civil Engineering, Hunan University, Hunan, Changsha 410082, China \\ ${ }^{2}$ Department of Building Engineering, Hunan Institute of Engineering, Hunan, Xiangtan 411104, China \\ ${ }^{3}$ Soochow University, Jiangsu, Suzhou 215137, China \\ ${ }^{4}$ Institute of Built Environment and Control, Zhongkai University of Agriculture and Engineering, \\ Guangdong, Guangzhou 510225, China
}

Correspondence should be addressed to Xiang-Long Liu, xianglongliu1@163.com

Received 13 January 2012; Accepted 20 February 2012

Academic Editor: M. F. El-Amin

Copyright (c) 2012 Xiang-Long Liu et al. This is an open access article distributed under the Creative Commons Attribution License, which permits unrestricted use, distribution, and reproduction in any medium, provided the original work is properly cited.

\begin{abstract}
Radiant floor heating has received increasing attention due to its diverse advantages, especially the energy saving as compared to the conventional dwelling heating system. This paper presents a numerical investigation of airflow and heat transfer in the slot-vented room with the radiant floor heating unit. Combination of fluid convection and thermal radiation has been implemented through the thermal boundary conditions. Spatial distributions of indoor air temperature and velocity, as well as the heat transfer rates along the radiant floor and the outer wall, have been presented and analyzed covering the domains from complete natural convection to forced convection dominated flows. The numerical results demonstrate that the levels of average temperature in the room with lateral slot-ventilation are higher than those without slot-ventilation, but lower than those in the room with ceiling slot-ventilation. Overall, the slot-ventilation room with radiant floor heating unit could offer better indoor air quality through increasing the indoor air temperature and fresh air exchanging rate simultaneously. Concerning the airborne pollutant transports and moisture condensations, the performance of radiant floor heating unit will be further optimized in our future researches.
\end{abstract}

\section{Introduction}

Radiant floor heating is a novel indoor heating technique that has received increasing attention in recent years. In the conventional heating methods, such as the air convection by radiators and the hot air supply by air conditioners, the hot air is always located in the upside or middle upside of the room instead of the occupied zone, leading to the obvious 
temperature differences between the upside and underside of the room. Under such condition, occupants usually feel uncomfortable. In the radiant floor heating, however, the effective temperature of the floor is higher than the temperature in the upside of the room, which can supply more heat to the underside of the room for warming the occupants' feet instead of their heads that follows the rule of human's physiologic adjustment. Therefore, the radiant floor heating improves the thermal comfort condition for the occupants as compared to the conventional heating methods. In addition, the radiant system has the advantages of energy saving, long life, wide selection of the heat sources, low cost, and environmental friendliness. The theoretical and experimental research $[1,2]$ showed that radiant floor system can decrease more than $30 \%$ of the energy consumption. The radiant floor system is also used for indoor cooling in summer only by changing the heat source to the cool source. In recent years, the indoor radiant heating or cooling system has been receiving increasing utilization in residential and commercial buildings. For example, among the newly built European buildings, many of them have been equipped with the radiant heating/cooling systems.

Radiant heating system is such a complex system that involves the various heat transfer mechanisms, including the heat conduction in the floor, the radiative heat transfer between radiant surface and other surfaces, convective heat transfer between the radiant surface and its neighboring air, and the buoyancy's effects. The numerical method provides a convenient way to solve such problem. Ghaly and Elbarbary [3] and Shateyi [4] numerically studied the convection coupled with radiative heat transfer and buoyancy's effects. Ma et al. [5] numerically studied the characteristics of the temperature and velocity distribution in the room, and their results showed that radiant heat flux accounted for $50-60 \%$ of the total heat flux. Sattari and Farhanieh [6] studied the effects of design parameters on performance of a typical radiant floor heating system using finite element method. Bozkir and Canbazoğlu [7] carried out the experimental and numerical research on the radiant heating system with an attempt to find the characteristics. In practice, the adequate fresh air supply is usually required to ensure indoor air quality. As a result, the floor radiant heating system is usually combined with the slot-ventilation system. However, few of the research works focuses on the air flow and heat transfer in the slot-vented room with radiant floor heating unit.

This paper presents the numerical simulation of floor radiant heating system with three types of slot-ventilation, that is, lateral slot-ventilation (LSV), ceiling slot-ventilation (CSV) and no slot-ventilation (NSV). The indoor temperature, velocity, and heat flux distributions are calculated. This work is of great significance for the design and wider application of the floor radiant heating system.

\section{Mathematical Model}

The steady 2D model of the turbulent airflow and heat transfer in the room is developed in this study. The schematic of radiant heating system and coordinate system is shown in Figure 1 . The radiant floor is assumed as the constant temperature $T_{\mathrm{fl}}$; the outside wall is cooled at the constant heat flux $q_{\text {ow }}$; other walls are adiabatic. The air velocity at the inlet is $u_{\text {in }}$, and the inflow temperature is $t_{\text {in }}$. The standard $K-\varepsilon$ two equations are used to describe the turbulent flow and the governing equations are given as follows.

Continuity equation:

$$
\frac{\partial(\rho u)}{\partial x}+\frac{\partial(\rho v)}{\partial y}=0
$$




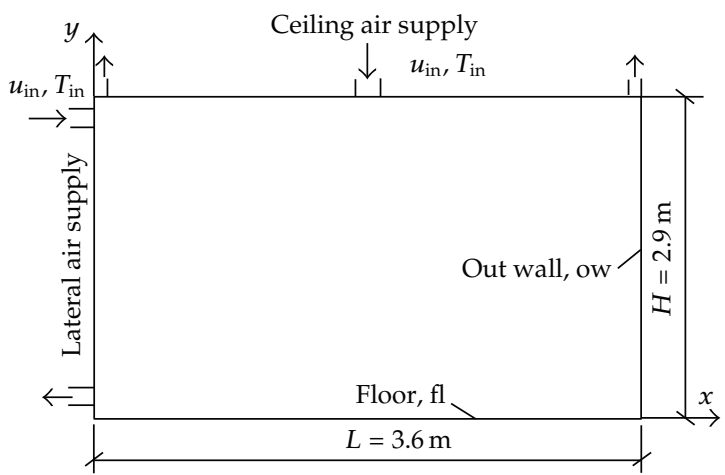

Figure 1: Schematic of radiant heating system and coordinate system.

Momentum equations:

$$
\begin{aligned}
\frac{\partial(\rho u u)}{\partial x}+\frac{\partial(\rho v u)}{\partial y}= & \frac{\partial}{\partial x}\left(\mu_{\mathrm{eff}} \frac{\partial u}{\partial x}\right)+\frac{\partial}{\partial y}\left(\mu_{\mathrm{eff}} \frac{\partial u}{\partial y}\right)-\frac{\partial p}{\partial x} \\
& +\frac{\partial}{\partial x}\left(\mu_{\mathrm{eff}} \frac{\partial u}{\partial x}\right)+\frac{\partial}{\partial y}\left(\mu_{\mathrm{eff}} \frac{\partial v}{\partial x}\right) \\
\frac{\partial(\rho u v)}{\partial x}+\frac{\partial(\rho v v)}{\partial y}= & \frac{\partial}{\partial x}\left(\mu_{\mathrm{eff}} \frac{\partial v}{\partial x}\right)+\frac{\partial}{\partial y}\left(\mu_{\mathrm{eff}} \frac{\partial v}{\partial y}\right)-\frac{\partial p}{\partial y} \\
& -\rho g+\frac{\partial}{\partial x}\left(\mu_{\mathrm{eff}} \frac{\partial u}{\partial y}\right)+\frac{\partial}{\partial y}\left(r \mu_{\mathrm{eff}} \frac{\partial v}{\partial y}\right),
\end{aligned}
$$

where $u, v$ are the fluid velocities in $x$-and $y$-directions respectively; $p$ is the pressure of the fluid; $g$ represents the acceleration of gravity. $\mu_{\text {eff }}$ is effective viscosity coefficient, which is equal to the sum of molecular viscosity $\mu$ and turbulent eddy viscosity $\mu_{\mathrm{t}}$. Turbulent eddy viscosity $\mu_{\mathrm{t}}$ is determined by the local turbulent kinetic energy $K$ and the dissipation rate $\varepsilon$ :

$$
\mu_{\mathrm{t}}=\frac{c_{\mu} \rho K^{2}}{\varepsilon}
$$

Energy equation in terms of temperature $T$ is given below

$$
\frac{\partial(\rho u T)}{\partial x}+\frac{\partial(\rho v T)}{\partial y}=\frac{\partial}{\partial x}\left(\left(\frac{\lambda}{c_{p}}+\frac{\mu_{t}}{\sigma_{T}}\right) \frac{\partial T}{\partial x}\right)+\frac{\partial}{\partial y}\left(\left(\frac{\lambda}{c_{p}}+\frac{\mu_{t}}{\sigma_{T}}\right) \frac{\partial T}{\partial r}\right) .
$$


Transport equations for turbulent kinetic energy $K$ and dissipation rate equations $\varepsilon$ are

$$
\begin{gathered}
\frac{\partial(\rho u K)}{\partial x}+\frac{\partial(\rho v K)}{\partial y}=\frac{\partial}{\partial x}\left(\left(\mu+\frac{\mu_{t}}{\sigma_{k}}\right) \frac{\partial K}{\partial x}\right)+\frac{\partial}{\partial r}\left(\left(\mu+\frac{\mu_{t}}{\sigma_{k}}\right) \frac{\partial K}{\partial y}\right)+G-\rho \varepsilon \\
\frac{\partial(\rho u \varepsilon)}{\partial x}+\frac{\partial(\rho v \varepsilon)}{\partial y}=\frac{\partial}{\partial x}\left(\left(\mu+\frac{\mu_{t}}{\sigma_{\varepsilon}}\right) \frac{\partial \varepsilon}{\partial x}\right)+\frac{\partial}{\partial r}\left(\left(\mu+\frac{\mu_{t}}{\sigma_{\varepsilon}}\right) \frac{\partial \varepsilon}{\partial y}\right)+\left(c_{1} G-c_{2} \rho \varepsilon\right) \frac{\varepsilon}{K^{\prime}}
\end{gathered}
$$

$G$ in (2.5) is the production term given by

$$
G=\mu_{t}\left\{2\left[\left(\frac{\partial u}{\partial x}\right)^{2}+\left(\frac{\partial v}{\partial y}\right)^{2}+\left(\frac{v}{r}\right)^{2}\right]+\left(\frac{\partial u}{\partial y}+\frac{\partial v}{\partial x}\right)^{2}\right\}
$$

The closure coefficients $c_{\mu}, c_{1}, c_{2}, \sigma_{T}, \sigma_{K}$, and $\sigma_{\varepsilon}$ in the above turbulent model are set as constants $0.09,1.44,1.92,1.0,1.0$, and 1.3 , respectively [8].

The DO radiation model is employed to handle the radiative heat transfer, and the absorbing and scattering of air are omitted:

$$
\frac{d I(\vec{r}, \vec{s})}{d s}+a I(\vec{r}, \vec{s})=a \frac{\sigma T^{4}}{\pi}
$$

where $\vec{s}$ is the distance between the two points of different wall surfaces and $a$ is the absorption coefficient. Each of the wall surfaces is assumed as grey-body radiation surfaces, and the radiation emissivity at the floor is $\varepsilon_{\mathrm{fl}}=0.6$, and are taken as 0.8 at the other surfaces.

\section{Numerical Method}

Based on the control volume and SIMPLEC method [9], the governing equations (2.1)-(2.7) subject to the boundary conditions are solved in the iterative manner. The grid is $x \times y=200 \times$ 180 , with the depressed mesh at near the wall to match the high velocity and temperature gradients. In the calculation, the Boussinesq assumption is used to consider the buoyancy's effect, and the thermal expansion coefficient $\beta$ is 0.0033 . The thermophysical properties of air are constant except the density. The converged solution is obtained when the following convergence criteria are satisfied for the dependent variables:

$$
\left|\frac{\phi^{n+1}-\phi^{n}}{\phi^{n}}\right| \leq 10^{-5}, \quad \text { where } \phi=u, v, \text { and } T .
$$

\section{Results and Discussion}

The calculation conditions are as follows: the constant wall temperature $T_{\mathrm{fl}}=30^{\circ} \mathrm{C}$; the inlet velocity $u_{\text {in }}=0.3,0.6$ and $0.9 \mathrm{~m} / \mathrm{s}$; the cooling heat flux of the outside wall $q_{\mathrm{ow}}=$ $-100 \mathrm{~W} / \mathrm{m}^{2}$. The air temperature at the inlet is equal to the mass-averaged temperature without slot-ventilation so that no additional heat load is induced into the room. The indoor air temperature and velocity distributions, as well as the radiative and convective heat flux 
between radiant floor and outside wall, are calculated under the different slot-ventilation modes (i.e., LSV, CSV, and NSV).

\subsection{Velocity and Temperature Distributions}

Figure 2 shows the temperature and velocity distributions for the three slot ventilation modes at $T_{\mathrm{fl}}=30^{\circ} \mathrm{C}, q_{\mathrm{ow}}=-100 \mathrm{~W} / \mathrm{m}^{2}$, and $u_{\mathrm{in}}=0.6 \mathrm{~m} / \mathrm{s}$. The air temperature in the room is quite uniform (the temperature difference is less than $1^{\circ} \mathrm{C}$ ), except in the area near the floor. The air temperature is lower in the area near outside wall. As no fresh air is supplied for NSV (Figure 2(a)), the air near outside wall is firstly cooled down and then moves downward due to the density difference in the vertical direction. The cooled air flows along the floor due to the stagnation effect as it touches the floor and is warmed up at the floor. Then the heated air moves upwards along the inside wall due to the buoyancy' effect. As a result, the clockwise natural convection of indoor air is formed. It is clearly seen that only in the region near the wall the obvious air flow is observed, and the velocity is quite low elsewhere. As shown in Figure 2(b), the indoor air temperature is higher under LSV mode as compared to the case with NSV. Because both the air inlet and air outlet are installed at the same inside wall (one is near the ceiling and the other is near the floor), the attaching jet flow is formed along the ceiling as the air is supplied. The air is then cooled near the outside wall and goes downwards so that the flow pattern similar to the natural convection is formed, but the air velocity is higher for LSV. Due to the higher air velocity along the walls, the convective heat transfer between the air and the wall is enhanced for LSV. Under CSV, (Figure 2(c)), the indoor air temperature is further increased, and the air flow pattern is quite different from those under above-mentioned two modes. As the air is supplied from the middle of ceiling, the air from the inlet is continuously expanded and decelerated along the flow direction. The supplied air is divided into two parts; one flows towards the outlet and is exhausted, and the other flows towards to the outside wall which is cooled and goes down, forming the same flow pattern as the natural convection. As the magnitude of the air velocity is close to that of natural convection velocity, the flow pattern is the combined result of the forced convection and the natural convection.

Figure 3 shows the temperature distribution at the different locations for the cases shown in Figure 2. In this figure, $X, Y$ are dimensionless distance $X=x / L, Y=y / H$. It is found that the average temperature for CSV is highest, while the average temperature for NSV is lowest. For all the cases, the temperature gradients along the height direction are quite small except in the area near the floor and ceiling, which indicates the uniform temperature distribution in most of the area. The temperature gradients near the floor are quite large, especially in the area closer to outside wall (e.g., $X=0.8$ ). This is because the air cooled at the outside wall produces the greater temperature difference as it is passing along the floor. Near the ceiling, because of the influences of the radiation, convection, cooling from the outside wall, heat transfer mechanism is complex. As a result, the obvious temperature gradient is also observed near the ceiling.

Figure 4 shows the velocity distribution at different locations for the cases shown in Figure 2. It is clearly found that the influence of the slot-ventilation on the flow pattern is obvious. Under these three conditions, air velocity in the occupied zone is all less than $0.2 \mathrm{~m} / \mathrm{s}$, while the air velocity of the area near the ceiling and floor is as high as $0.5 \mathrm{~m} / \mathrm{s}$. Compared to NSV, the velocity near the floor and the ceiling for LSV and CSV is much higher, and CSV leads to the more complex flow pattern. 

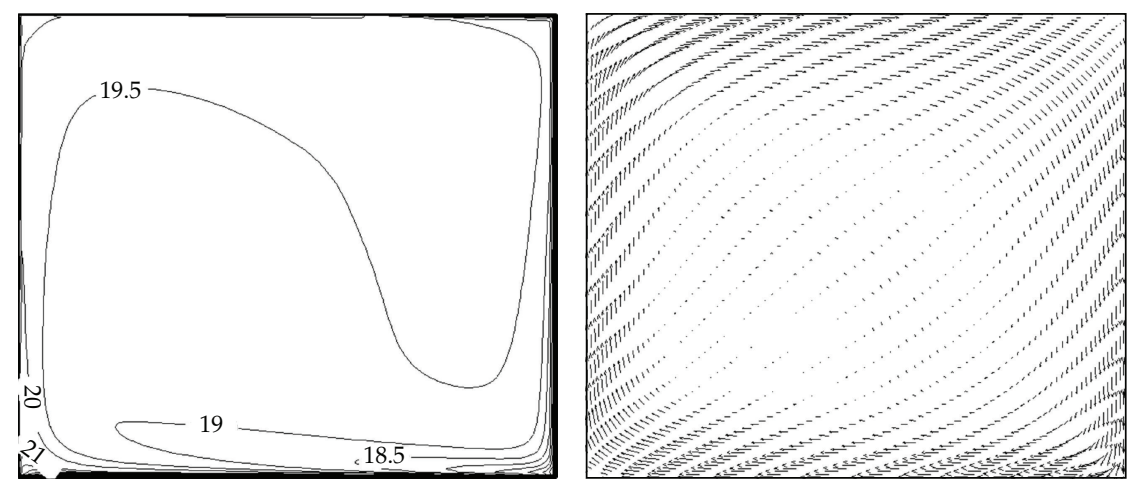

(a)
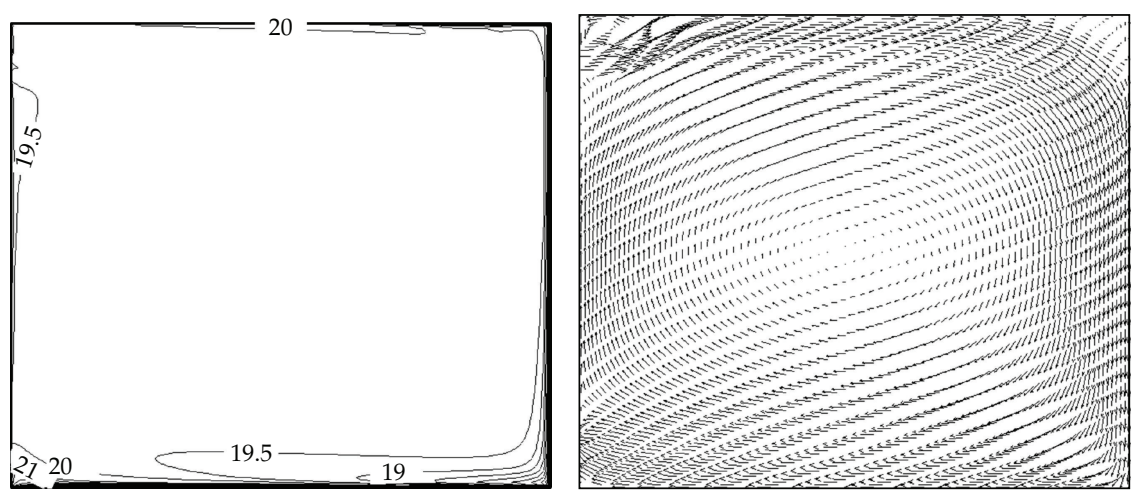

(b)
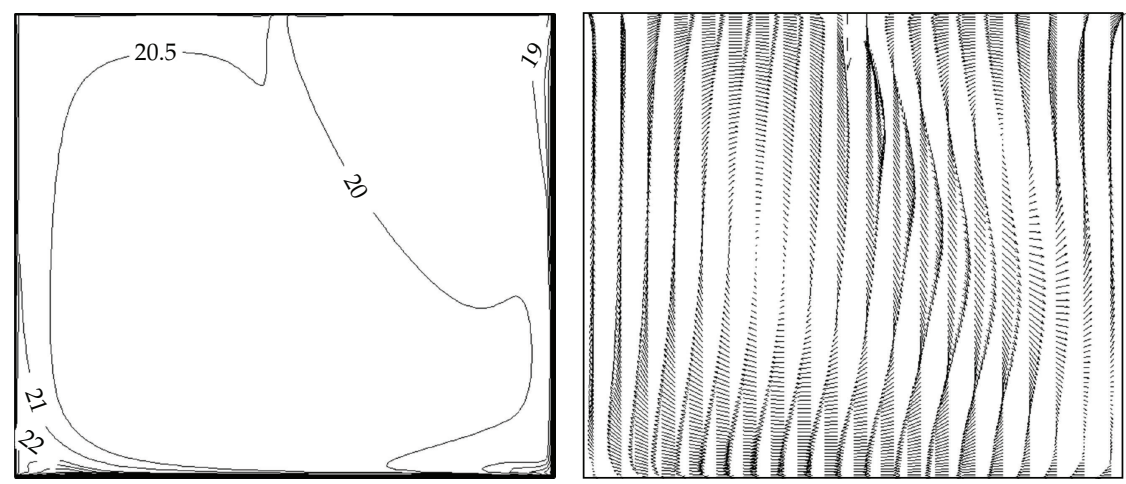

(c)

Figure 2: The temperature and velocity distribution at $T_{\mathrm{fl}}=30^{\circ} \mathrm{C}, q_{\mathrm{ow}}=-100 \mathrm{~W} / \mathrm{m}^{2}$ and $u_{\text {in }}=0.3 \mathrm{~m} / \mathrm{s}$ for (a) no slot-ventilation (NSV), (b) lateral slot-ventilation (LSV), and (c) ceiling slot-ventilation (CSV).

Figure 5 shows the temperature and velocity distributions for LSV at $T_{\mathrm{fl}}=30^{\circ} \mathrm{C}, q_{\mathrm{ow}}=$ $-100 \mathrm{~W} / \mathrm{m}^{2}$, and $u_{\text {in }}=0.3$, and $0.9 \mathrm{~m} / \mathrm{s}$. It is clear that the airflow pattern and temperature distributions are similar to the case shown in Figure $2(\mathrm{~b})$. As the inlet velocity increases $\left(u_{\text {in }}=\right.$ $0.9 \mathrm{~m} / \mathrm{s}$ ), (Figure 5(a)), more air flows towards the outside wall, leading to the more intensive convective heat transfer between the indoor air and the outside wall. As a result, the air is cooled to the lower temperature. For this reason, the bulk temperature of the indoor air 

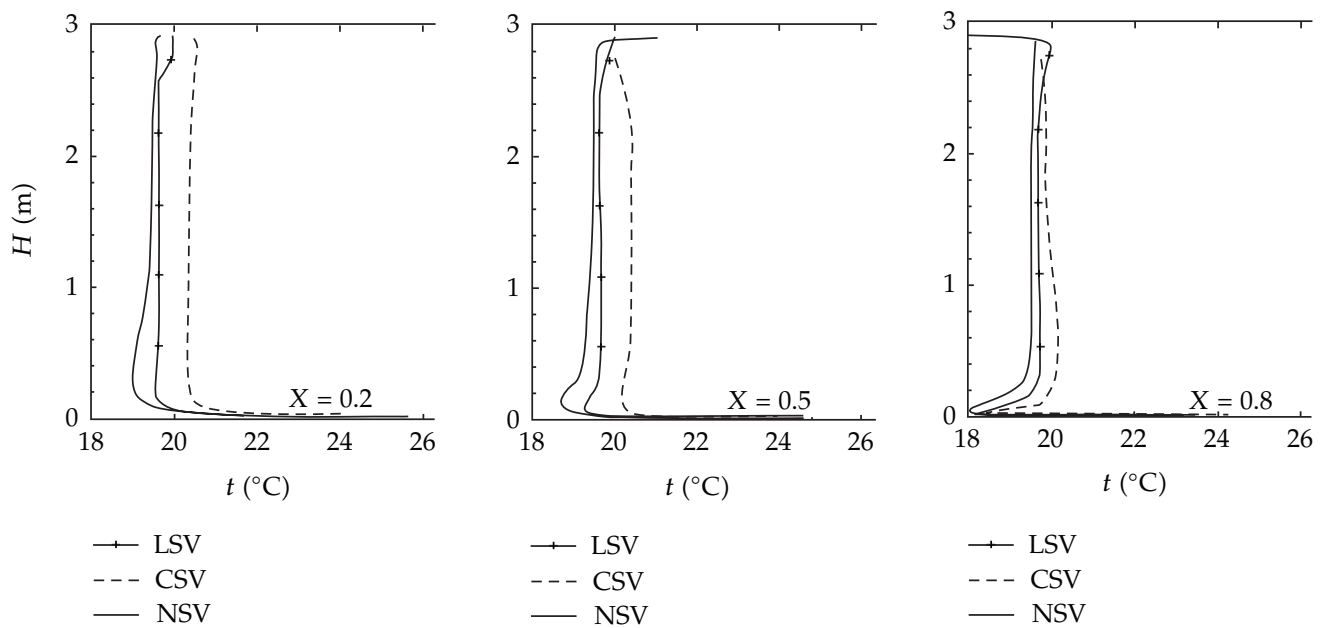

Figure 3: The temperature distributions at different $X$ locations for the cases shown in Figure 2.
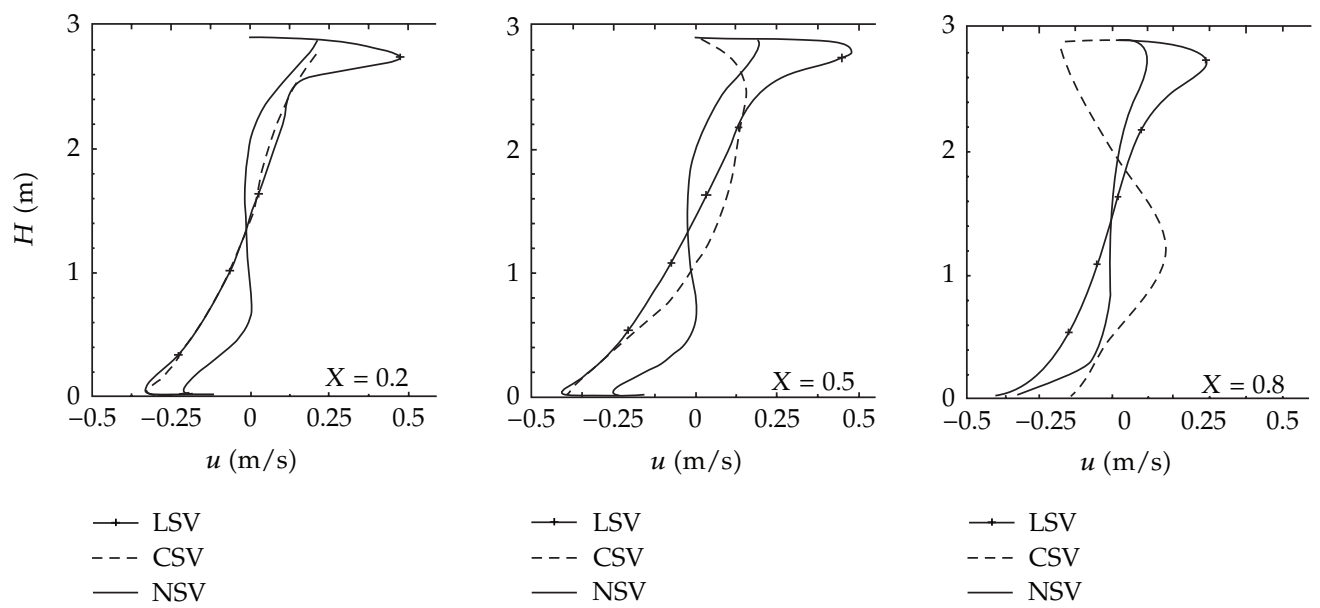

Figure 4: The velocity distributions at different $X$ locations for the cases shown in Figure 2.

is lower. In reverse, as the inlet velocity is lower $\left(u_{\text {in }}=0.3 \mathrm{~m} / \mathrm{s}\right.$ ) (Figure $\left.5(\mathrm{~b})\right)$, less air reaches the outside wall, and the bulk temperature of the indoor air is higher because of the weaker convective heat transfer along the outside wall.

Figure 6 shows the temperature and velocity distributions for CSV at $T_{\mathrm{fl}}=30^{\circ} \mathrm{C}, q_{\mathrm{ow}}$ $=-100 \mathrm{~W} / \mathrm{m}^{2}$, and $u_{\text {in }}=0.3$ and $0.9 \mathrm{~m} / \mathrm{s}$. The airflow pattern and temperature distributions are similar to the case shown in Figure 2(c). As the inlet velocity increases $\left(u_{\text {in }}=0.9 \mathrm{~m} / \mathrm{s}\right)$ (Figure 6(a)), more air flows are supplied, leading to the more intensive convective heat transfer between the air and the outside wall and the floor. However, because the direction of the inlet velocity is towards the floor, the convective and radiative heat transfer along the floor are dominant. As a result, the bulk temperature of the air in the room is higher. In reverse, as the inlet velocity is lower $\left(u_{\text {in }}=0.3 \mathrm{~m} / \mathrm{s}\right.$ ) (Figure $\left.6(\mathrm{~b})\right)$, the convective heat transfer along both the outside wall and the floor decreases, which decreases the bulk air temperature in the room as compared to the case of $u_{\text {in }}=0.9 \mathrm{~m} / \mathrm{s}$. However, the air temperature at $u_{\text {in }}=0.3 \mathrm{~m} / \mathrm{s}$ 


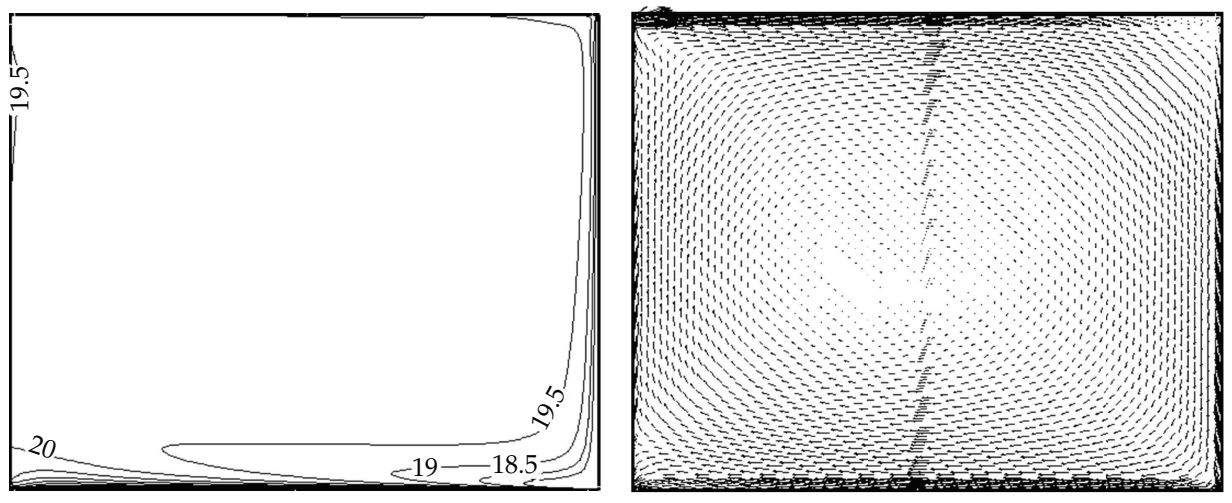

(a)
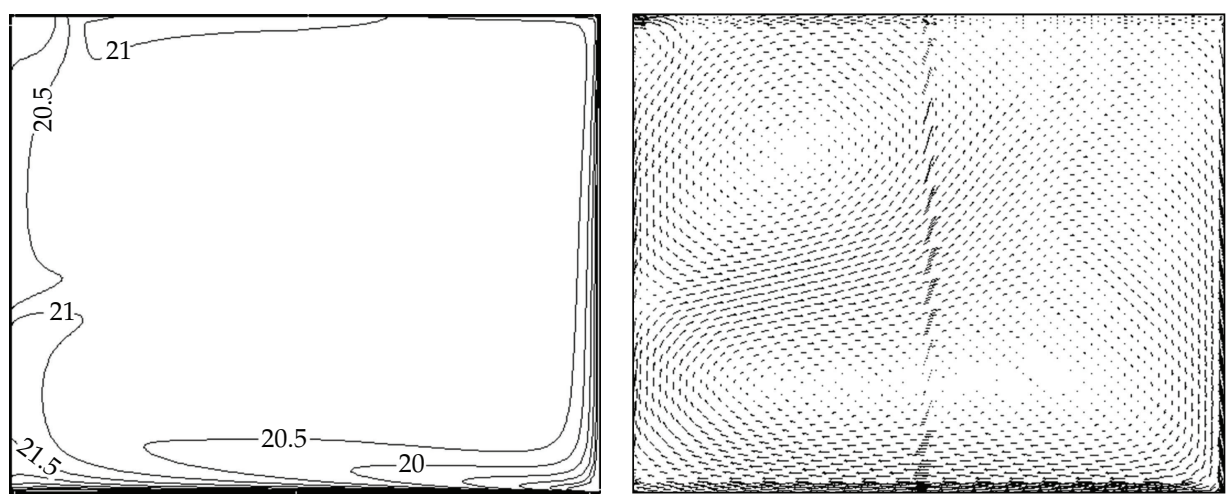

(b)

Figure 5: The velocity and temperature distributions for LSV at $T_{\mathrm{fl}}=30^{\circ} \mathrm{C}, q_{\mathrm{ow}}=-100 \mathrm{~W} / \mathrm{m}^{2}$, (a) $u_{\text {in }}=$ $0.3 \mathrm{~m} / \mathrm{s}$, and (b) $u_{\mathrm{in}}=0.9 \mathrm{~m} / \mathrm{s}$.

is higher than that for $u_{\text {in }}=0.6 \mathrm{~m} / \mathrm{s}$. Therefore, the air temperature is related to the intensities of the convective heat transfer along the outside wall and the floor. There exists an optimal inlet velocity for CSV to increase the bulk temperature of the indoor air.

\subsection{Characteristics of Radiative and Convective Heat Transfer}

The different behaviors of the indoor air temperature under the different conditions are the combined results of the different heat transfer mechanisms. The heat fluxes along the floor and outside wall are studied and the Nusselt numbers for the convective heat transfer $N u_{c}$ and the radiative heat transfer $N u_{r}$ along the wall surface are given. Radiative heat flux $q_{r}$ and convective heat flux $q_{c}$ are defined as

$$
\begin{gathered}
q_{r}=\int_{\Omega} \sigma\left(\varepsilon_{w^{\prime}} T_{w^{\prime}}^{4}-\alpha_{w} T_{w}^{4}\right) \frac{\cos \theta_{1} \cos \theta_{2}}{\pi s^{2}} d A_{w^{\prime}} \\
q_{c}=-\left.\lambda \frac{\partial T}{\partial r}\right|_{W^{\prime}}
\end{gathered}
$$



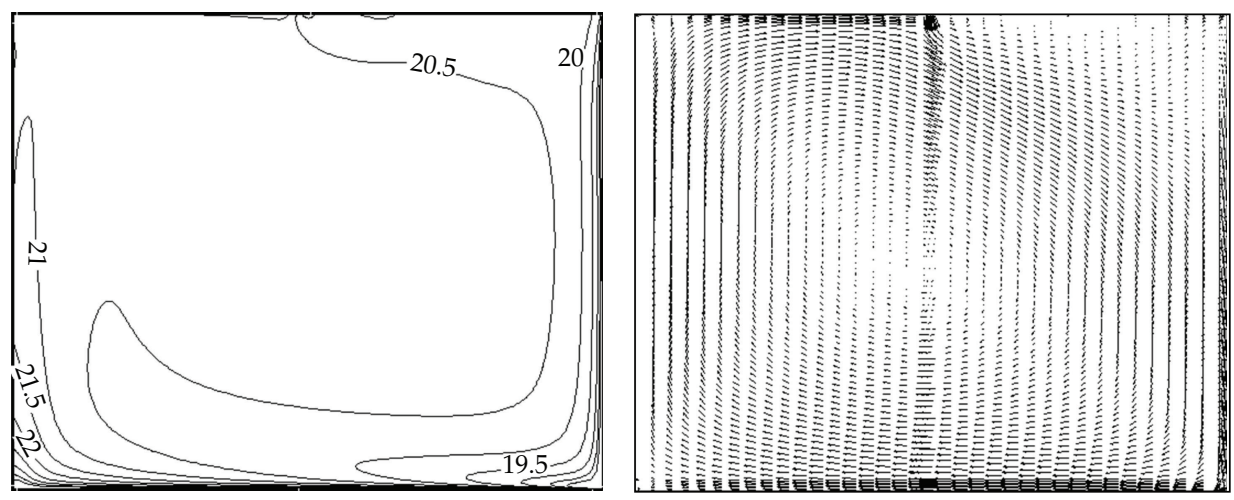

(a)
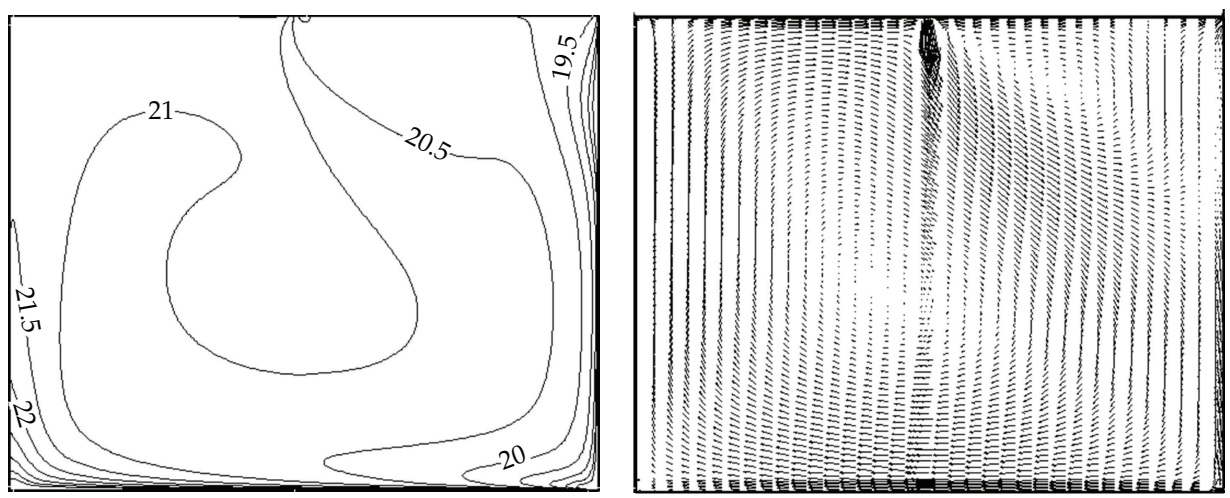

(b)

Figure 6: The velocity and temperature distributions for CSV at $T_{\mathrm{fl}}=30^{\circ} \mathrm{C}, q_{\mathrm{ow}}=-100 \mathrm{~W} / \mathrm{m}^{2},(\mathrm{a}) u_{\mathrm{in}}=$ $0.3 \mathrm{~m} / \mathrm{s}$, and (b) $u_{\mathrm{in}}=0.9 \mathrm{~m} / \mathrm{s}$.

where $q_{r}$ is net radiative heat flux between the cells $w$ at the outside wall or floor and $w^{\prime}$ at other walls; $s$ is the distance of two points; $\theta_{1}$ and $\theta_{2}$ are the angles to the surface normal, and $\lambda$ is heat conductivity. The radiative and convective heat transfer coefficients are defined as $\alpha_{r}$ and $\alpha_{c}$ :

$$
\begin{aligned}
& \alpha_{c}=\frac{q_{c}}{\left(T_{w}-T_{b}\right)}, \\
& \alpha_{r}=\frac{q_{r}}{\left(T_{w}-T_{b}\right)},
\end{aligned}
$$

where $T_{b}$ is the bulk temperature of indoor air, $N u$ can be calculated through $N u=\alpha l_{e} / \lambda$, in which $l_{e}$ is characteristic length, which is taken as $3.6 \mathrm{~m}$ for the floor and $2.9 \mathrm{~m}$ for the outside wall.

Figures 7 and 8, respectively, present the distributions of $N u_{c}$ and $N u_{r}$ distribution along with floor and outside wall for the cases shown in Figure 2. It is found that $N u_{r}$ is greater than $N u_{c}$ in most of the areas under the different conditions, which indicates that the radiative heat transfer is stronger than the convective heat transfer. For NSV, the radiative heat flux accounts for about $56 \%$ of the total heat flux. For LSV and CSV, the percentages of the 


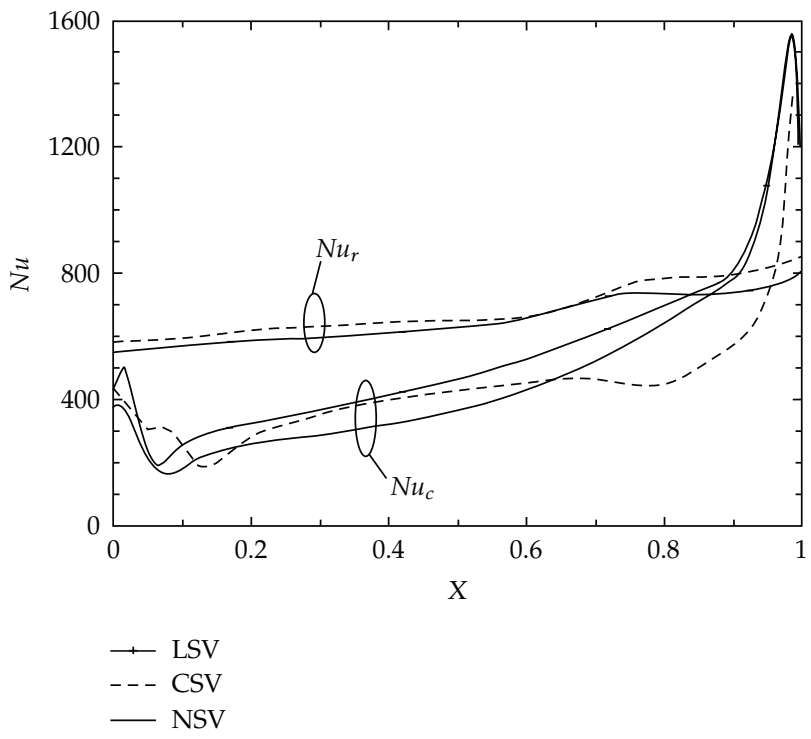

Figure 7: $N u_{c}$ and $N u_{r}$ distributions along the floor for the cases shown in Figure 2.

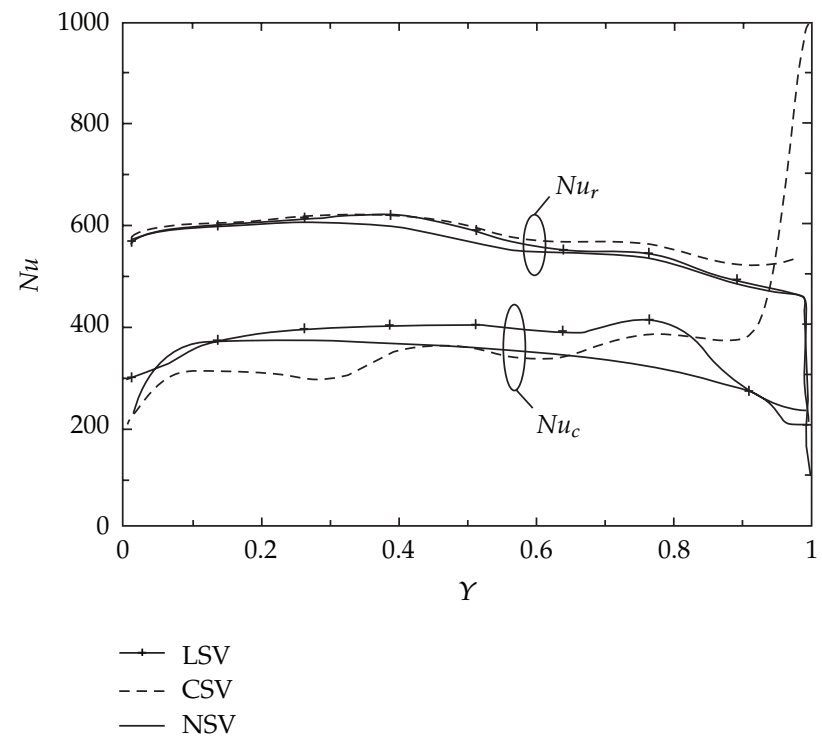

Figure 8: $N u_{c}$ and $N u_{r}$ distribution along the outside wall for the cases shown in Figure 2 .

radiative heat transfer are about $54 \%$ and $61 \%$, respectively. In the area near the outside wall, the intense convection is observed due to the local vortex and higher temperature gradients (Figure 3) and thus $N u_{c}$ is greater $N u_{r}$, indicating the stronger convective heat transfer in this area. The magnitude of the radiative heat flux increases with the increased $X$; therefore, the radiation is more significant in the area closer to the low-temperature outside wall. Under LSV and NSV, the air velocity and hence $N u_{c}$ decrease with the decreased $\mathrm{X}$. The velocity under CSV increases firstly and then decreases along $\mathrm{X}$, and $N u_{c}$ has the same tendency. 
Near the inside wall, the local vortex is formed that increases the convective heat transfer and thus $N u_{c}$ increases to some extent. There is no significant difference between $N u_{r}$ under the three conditions. For LSV, $N u_{c}$ is of the largest magnitude as the result of the strongest convective heat transfer. As $X<0.67, N u_{c}$ for CSV is greater than that for NSV. It is also found from Figure 8 that $N u_{r}$ is greater than $N u_{c}$ for all the three conditions except in the area near air inlet for the CSV $(Y>0.95)$, which suggests that the radiation dominates the heat transfer mechanism. Under LSV, $N u_{c}$ is larger as $Y<0.85$ as compared to the two other cases, indicating the strongest convection heat transfer in this area. As $Y>0.85$, for CSV, the air velocity significantly increases near the inlet, which increases the convection heat transfer.

\section{Conclusions}

The numerical stimulations of the airflow and heat transfer in the slot-vented room with radiant floor heating unit, including LSV, CSV, and NSV, are performed. The temperature, velocity, and the behaviors of the radiative and convective heat transfer are calculated. The results show that the air temperatures in the room are quite uniform under these three airsupply modes and the average temperature difference is less than $1^{\circ} \mathrm{C}$. Under LSV, the forced ventilation has the same moving direction with the natural convection and thus increases the air velocity. Under CSV, the flow pattern is more complex as the combined result of the forced ventilation and natural convection. Radiation is main heat transfer mechanism at the floor and the outside wall under all the three conditions. Radiative heat flux accounts for 50$60 \%$ of the total heat flux, which is largest under CSV. LSV offers the strongest convection along the floor and outside wall, which increases the convective heat transfer, especially at cold outside wall. Therefore, the average temperature for LSV is lower than that for CSV.

Concerning the airborne pollutant transports and moisture condensations, the performance of radiant floor heating unit will be further optimized in our future researches.

\section{Acknowledgments}

The authors gratefully acknowledge the funding for this project provided by International Science and Technology Cooperative Project of China (2010DFB63830), Major Science and Technology Project of Hunan Province (2010FJ1013), and National Natural Science Foundation of China (51178477).

\section{References}

[1] I. B. Kilkis, S. S. Sager, and M. Uludag, "A simplified model for radiant heating and cooling panels," Simulation Practice and Theory, vol. 2, no. 2, pp. 61-76, 1994.

[2] A. K. Athienitis and T. Y. Chen, "Experimental and theoretical investigation of floor heating with thermal storage," ASHRAE Transactions, vol. 99, no. 1, pp. 1049-1057, 1993.

[3] A. Y. Ghaly and E. M. E. Elbarbary, "Radiation effect on MHD free-convection flow of a gas at a stretching surface with a uniform free stream," Journal of Applied Mathematics, vol. 2, no. 2, pp. 93-103, 2002.

[4] S. Shateyi, "Thermal radiation and buoyancy effects on heat and mass transfer over a semi-infinite stretching surface with suction and blowing," Journal of Applied Mathematics, vol. 2008, Article ID 414830, 2008.

[5] L. D. Ma, W. Q. Tao, Y. Dai, and D. X. Sun, "Numerical simulation of temperature distribution and turbulent flow in the radiant floor heating room," Journal of Engineering Thermophysics, vol. 26, no. 3, pp. 501-503, 2005 (Chinese). 
[6] S. Sattari and B. Farhanieh, "A parametric study on radiant floor heating system performance," Renewable Energy, vol. 31, no. 10, pp. 1617-1626, 2006.

[7] O. G. Bozkir and S. Canbazoğlu, "Unsteady thermal performance analysis of a room with serial and parallel duct radiant floor heating system using hot airflow," Energy and Buildings, vol. 36, no. 6, pp. 579-586, 2004

[8] N. C. Markatos, "The mathematical modelling of turbulent flows," Applied Mathematical Modelling, vol. 10, no. 3, pp. 190-220, 1986.

[9] S. V. Partankar, Numerical Heat Transfer and Fluid Flow, McGraw-Hill, 1980. 


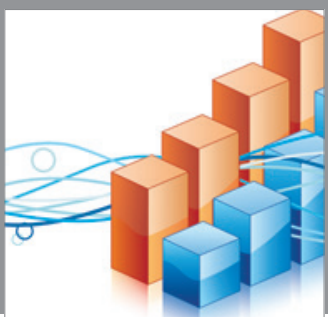

Advances in

Operations Research

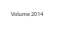

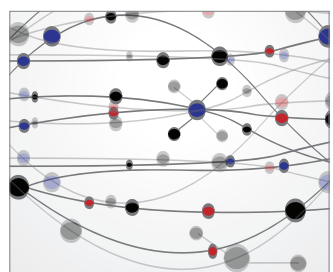

\section{The Scientific} World Journal
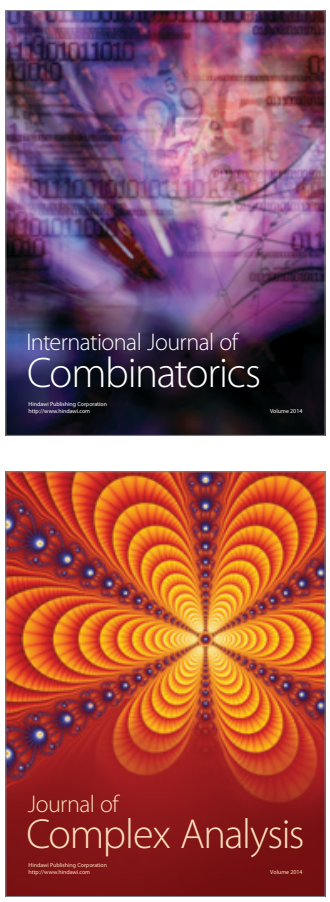

International Journal of

Mathematics and

Mathematical

Sciences
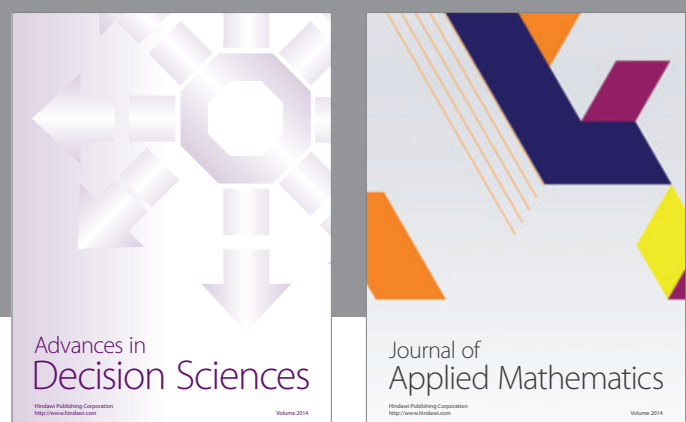

Journal of

Applied Mathematics
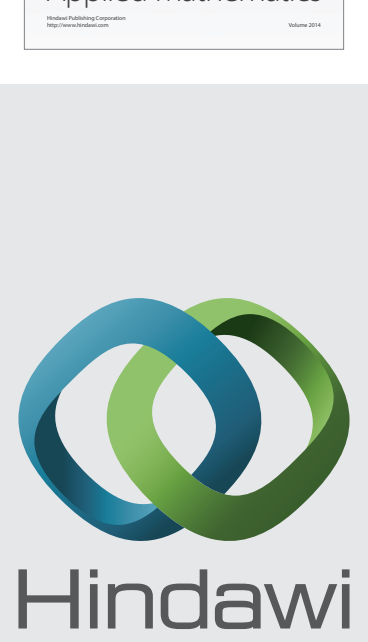

Submit your manuscripts at http://www.hindawi.com
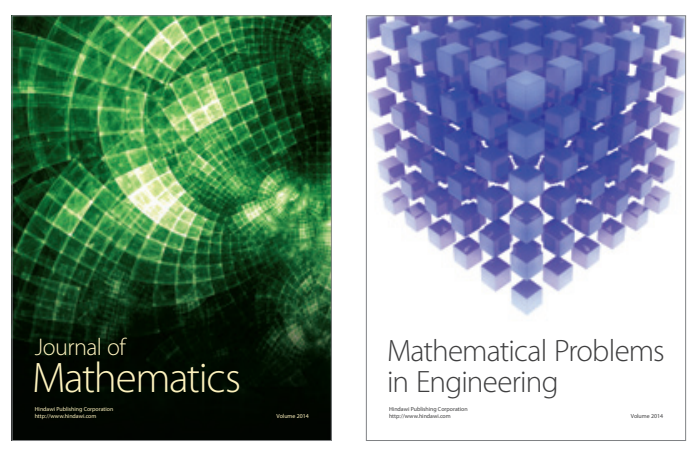

Mathematical Problems in Engineering
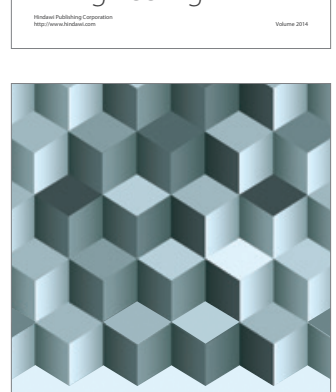

Journal of

Function Spaces
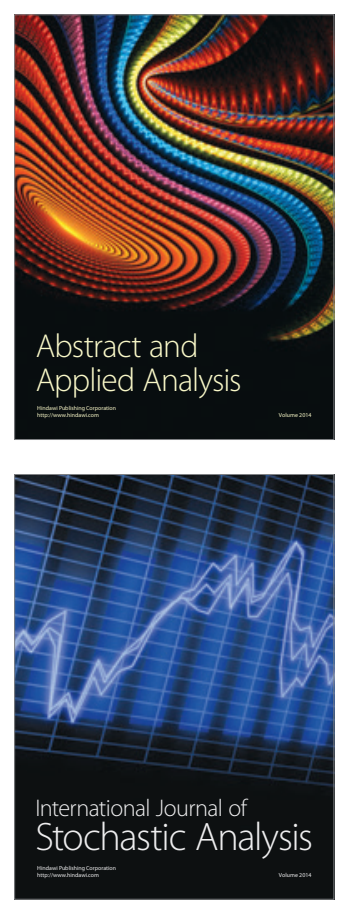

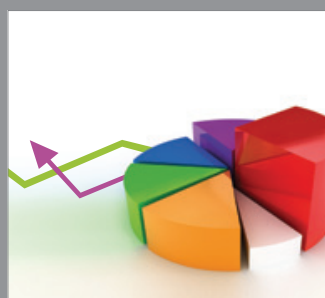

ournal of

Probability and Statistics

Promensencen
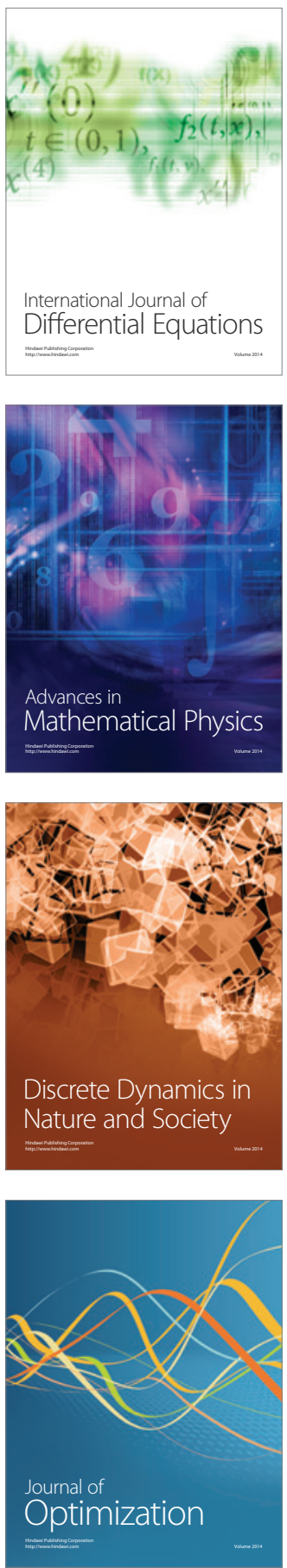